\title{
Artificial exosomes for translational nanomedicine
}

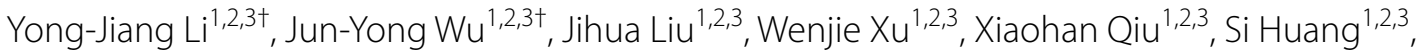 \\ Xiong-Bin $\mathrm{Hu}^{1,2,3}$ and Da-Xiong Xiang ${ }^{1,2,3^{*}}$
}

\begin{abstract}
Exosomes are lipid bilayer membrane vesicles and are emerging as competent nanocarriers for drug delivery. The clinical translation of exosomes faces many challenges such as massive production, standard isolation, drug loading, stability and quality control. In recent years, artificial exosomes are emerging based on nanobiotechnology to overcome the limitations of natural exosomes. Major types of artificial exosomes include'nanovesicles (NVs),' 'exosome-mimetic $(E M)$ ' and 'hybrid exosomes (HEs)', which are obtained by top-down, bottom-up and biohybrid strategies, respectively. Artificial exosomes are powerful alternatives to natural exosomes for drug delivery. Here, we outline recent advances in artificial exosomes through nanobiotechnology and discuss their strengths, limitations and future perspectives. The development of artificial exosomes holds great values for translational nanomedicine.
\end{abstract}

Keywords: Artificial, Biomaterials, Drug delivery, Exosomes, Nanomedicine

\section{Introduction}

In recent decades, synthetic nanoparticles (NPs) including liposomes [1], micelles [2], dendrimers [3], nanocapsules [4], nanodiamonds [5], nanosponges [6], nanoemulsions [7] and self-assembled peptides [8] have been extensively studied for nanomedicine, particularly for targeted cancer therapy. Drug delivery systems can improve the pharmacokinetic and pharmacodynamics profiles of therapeutics that carried, thereby enhancing the therapeutic effects while reducing undesired toxicity and side effects [9]. Despite undeniable success in the development of nanocarriers for drug delivery in preclinical and clinical studies, the past few decades have witnessed a limited number of approved nanomedicines and most of them are nanoliposomal formulations, Doxil [10-12], Mepact [13], Lipusu [14] and Abraxane [15-18] for example, for anticancer drug delivery.

\footnotetext{
*Correspondence: xiangdaxiong@csu.edu.cn

${ }^{\dagger}$ Yong-Jiang Li and Jun-Yong Wu contributed equally to this work

1 Department of Pharmacy, The Second Xiangya Hospital, Central South University, 139 Middle Renmin Road, Changsha 410011, China

Full list of author information is available at the end of the article
}

Exogenous nanomaterials for delivering drugs to the target site may face many hurdles, such as rapid clearance and various biological barriers [19]. It has been reported that only $0.7 \%$ of systemically administered NPs can reach the tumor mass [20], despite arguments in a recent reanalysis [21]. Clinical failure of synthetic NPs may be attributed to the differences in the biological barriers and immune systems between human and animal models [22]. NPs could be functionalized by conjugating with polyethylene glycol (PEG) to increase circulation times $[23,24]$ and by introducing antibodies or peptides $[25$, 26 to the surface to enhance the targeting capacity and change biodistribution. However, modifications of NPs still can hardly simulate complex biological components. Rapid clearance of PEGylated nanocarriers was observed after repeated administration due to systemic immunogenicity [27]. Besides, a specific ligand modification cannot guarantee high targeting efficiency due to heterogeneity of target cells.

One approach to overcome the limitations of synthetic NPs is developing natural carriers. The field of biological or bioinspired carriers for drug delivery has been original author(s) and the source, provide a link to the Creative Commons licence, and indicate if changes were made. The images or other third party material in this article are included in the article's Creative Commons licence, unless indicated otherwise in a credit line to the material. If material is not included in the article's Creative Commons licence and your intended use is not permitted by statutory regulation or exceeds the permitted use, you will need to obtain permission directly from the copyright holder. To view a copy of this licence, visit http://creativecommons.org/licenses/by/4.0/. The Creative Commons Public Domain Dedication waiver (http://creativeco mmons.org/publicdomain/zero/1.0/) applies to the data made available in this article, unless otherwise stated in a credit line to the data. 
advancing. Extracellular vesicles (EVs) [28], which are cell-derived proteolipid membrane vesicles, are emerging in nanomedicine-related fields [29]. Major types of EVs include exosomes, microvesicles, and apoptotic bodies [30]. Our understanding of the between-cell communication has been elevating in the last decade due to EVs, particularly exosomes, which are nano-sized (30-150 nm) subtype of EVs. Exosomes are enriched with various biological components, including proteins, nucleic acids and lipids from their parental cells [31]. Exosome-mediated cell-to-cell communication plays an important role in multiple physiological and pathological processes like tumor metastasis, drug resistance, immune responses and microenvironment homeostasis [32].

Exosomes are also competent candidates for targeted drug delivery [33-35]. Exosomes can escape phagocytosis and achieve long-term circulation by the 'don't eat me' signal for high levels of CD47 on exosomes and trigger CD47-SIRP $\alpha$ interaction that induce immune evasion [36, 37]. In addition, as endogenous cellular compartments, exosomes possess a wide range of cellular adhesion molecules facilitating their penetration through biological barriers. Despite promising results of exosome-mediated drug delivery in murine models, the translation of exosomes is challenged by massive production [38], purification [39], modification [40], drug loading [41] and storage [42]. Also, the heterogeneity between EV subpopulations greatly hindered the quality control for manufacturing and clinical translation [43, 44].

In view of the shortcomings of natural exosomes, a growing number of studies are aiming to develop artificial exosomes based on top-down, bottom-up or biohybrid technologies. Those artificial exosomes were generally called 'nanovesicles (NVs)', 'exosome-mimetics (EMs)' or 'hybrid exosomes (HEs)'. The development of artificial exosomes through nanobiotechnology hold great promises for advanced drug delivery with combined advantages of natural and synthetic NPs [45]. Here, we provide a comprehensive review of recent advances in nanofabrication of these artificial exosomes (Fig. 1) and discuss their challenges and future perspective for translational nanomedicine.

\section{Artificial exosomes by nanobiotechnology Top-down strategies}

For NPs production, top-down strategies have been used by disintegrating big and complex units into elements with smaller sizes. Exosomes are released from cells, herein, the production of artificial exosomes by topdown strategies generally starts from parent cells. Following the top-down strategy, cells are disassembled to form NVs. Therefore, the membrane composition of NVs by top-down strategies is similar to membrane of natural exosomes as they are generated directly from producer cells. NVs from top-down approaches possess natural proteins, nucleic acid or lipids from cells, mimicking the biological complexity of natural exosomes, but may have less heterogeneity. NVs are self-assembled and could be obtained with a few steps [46]. However, the purification methods for NVs are generally based on ultracentrifugation (UC), which is also a time-consuming process commonly used for exosome isolation [47]. Currently, several different fabrication approaches within top-down strategy have been reported for producing NVs by manipulating producer cells (Table 1).

\section{Extrusion-based approaches}

Extrusion over polycarbonate membrane filters is widely used to obtain NPs, such as liposomes, with controlled size distribution [71]. By serial extruding through polycarbonate membrane filters with diminishing pore sizes, cells can be turned into NVs with reduced size but maintaining the topology of plasma membrane proteins [46]. For extrusion-based approaches, NVs are generally produced with a simple commercial liposome extruder [72], but other devices have also been designed for scalable and semi-automatic production.

Jang et al. firstly developed bioinspired NVs by extruding human monoblastic U937 cells and mouse macrophage Raw264.7 cells through $10 \mu \mathrm{m}, 5 \mu \mathrm{m}$ and $1 \mu \mathrm{m}$ filters, followed by density gradient UC at 100,000 g [46]. They reported that NVs are similar to natural exosomes in terms of morphology, size, protein markers as well as anticancer efficacy after loading of chemotherapeutics. Importantly, NVs have significantly higher yield (100fold) than natural exosomes. Further, this research group generated NVs from various cells using established protocols and reported different applications including: NVs from embryonic stem cells can enhance cell proliferation [49]; mouse fibroblast NIH3T3 cells derived NVs can be used for efficient siRNA delivery [48]; NIH3T3 fibroblasts and MIN6 pancreatic $\beta$-cells-derived NVs can induce in vivo differentiation of therapeutic insulin-producing cells [50]; adipose stem cell (ASC)-derived NVs can serve as alternatives to ACS for similar beneficial effects in animals with emphysema [51]; mesenchymal stem cell (MSC)-derived NVs can be used for breast tumor drug delivery or directly for spinal cord injury treatment [52]. Besides, Yang et al. reported that human breast epithelial MCF10A cells derived NVs-mediated delivery of siRNA to MCF-7 breast cancer cells exhibited significant anticancer efficacy with reduced expression of CDK4 protein [54]; they also found that cellular clathrin-mediated and caveolin-mediated endocytosis play important roles in the uptake pathway of NVs. To understand protein components of NVs compared to exosomes, Kenari et al. 


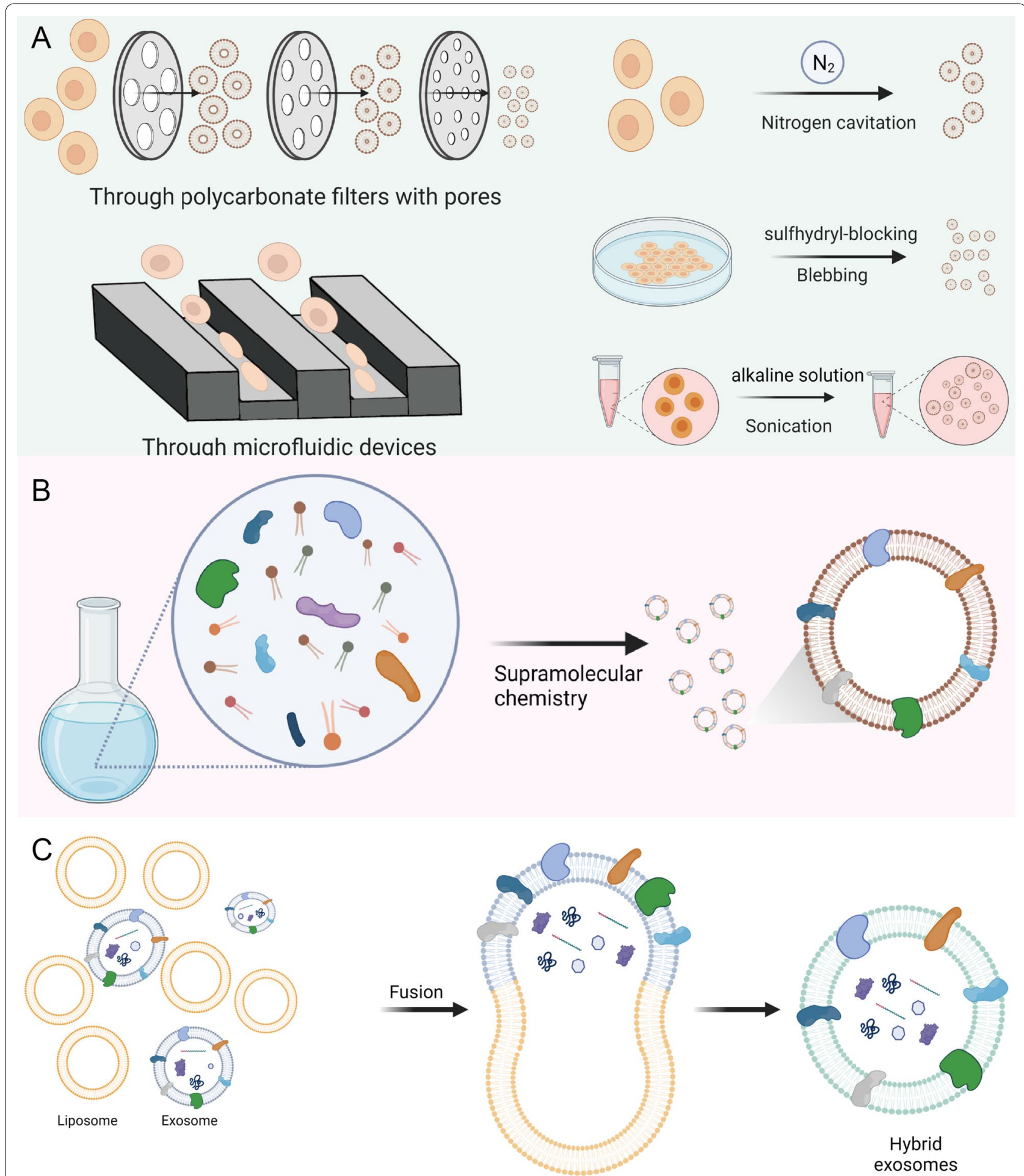

Fig. 1 Main strategies for obtaining artificial exosomes based on nanobiotechnology. A Top-down strategies for generating nanovesicles (NVs) by manipulating cells. Cells can be forced to pass through membrane pores or microfluidic devices to form NVs; cells can be disrupted by nitrogen cavitation to form NVs; sulfhydryl-blocking can lead to the release of small NVs from cells by cell membrane blebbing; cells exposed to alkaline solution will be broken into membrane sheets, which can form small NVs by sonication. B bottom-up strategies for generating fully artificial exosomes by supramolecular chemistry; synthetic materials (lipids) and key components (proteins) from cells can be combined to form exosome-mimetics (EMs) by supramolecular chemistry. C Biohybrid strategies for generating hybrid exosomes by fusing exosomes with liposomes. Isolated natural exosomes and synthetic liposome nanoparticles can be fused into hybrid exosomes (HEs) without affecting their intrinsic properties. 


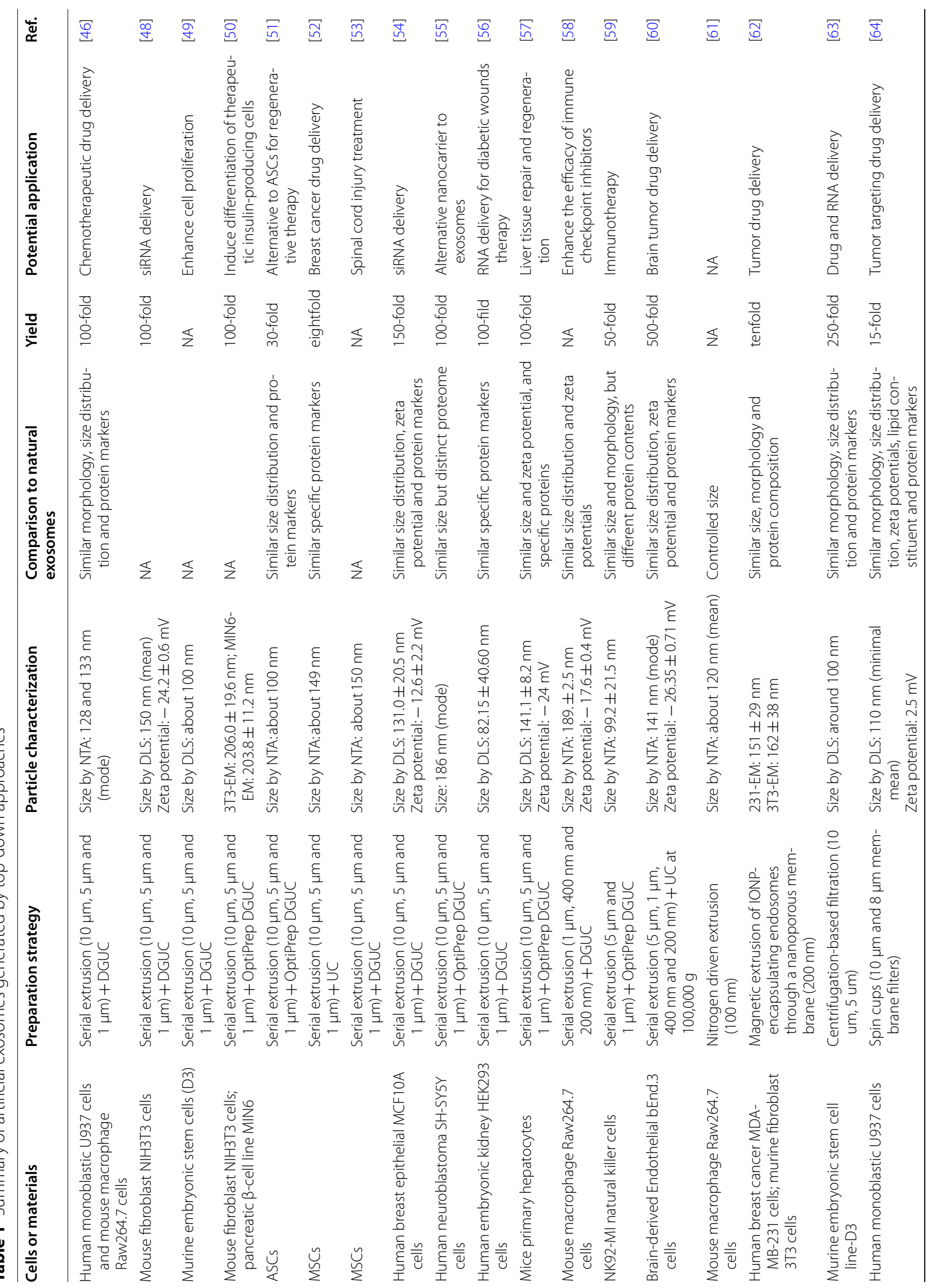




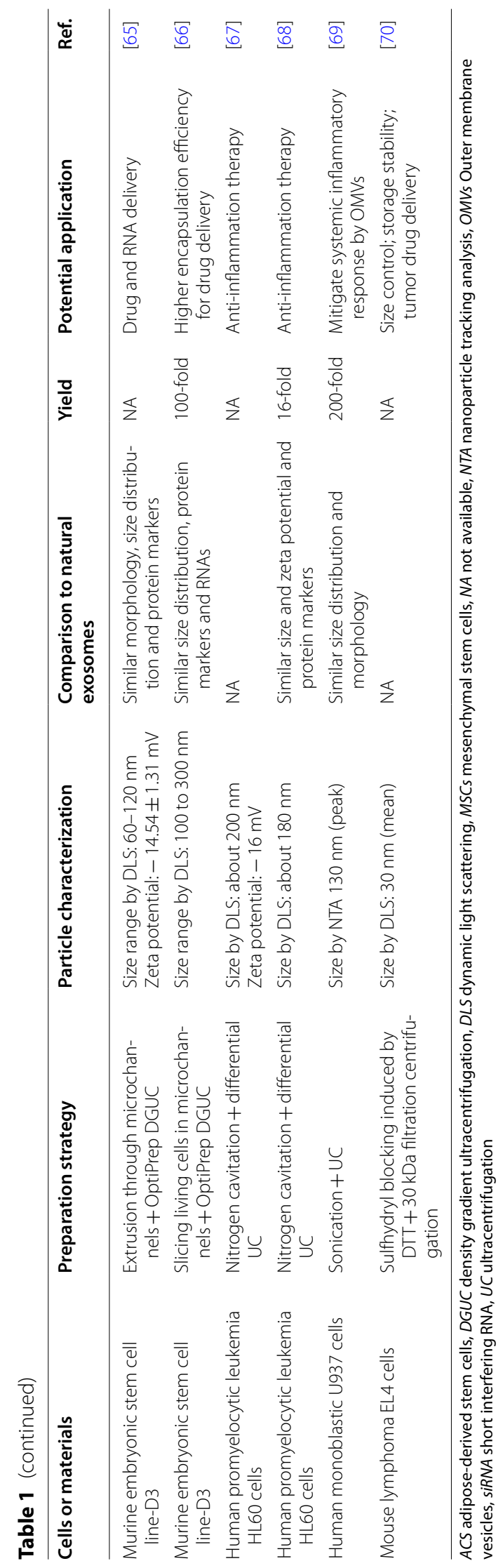


generated human neuroblastoma SH-SY5Y cells-derived $\mathrm{NVs}$ and natural exosomes and performed the proteomic analysis [55]. They found that NVs and exosomes are similar in size distribution, however, NVs exhibited parental cell-like proteome while exosomes exhibited endosomallike proteome. Differences in post-translational modification of proteins between NVs and exosomes were highlighted, but this would not affect the potential advantage of NVs as an alternative to exosomes for drug delivery. Tao et al. generated human embryonic kidney (HEK) 293 cell-derived NVs with small size $(82.15 \pm 40.60 \mathrm{~nm})$ and studied the function of NVs loaded with a high content of LncRNA-H19, which showed a strong ability to neutralize the regeneration-inhibiting effect of hyperglycemia for accelerating chronic wound healing of diabetes mellitus [56]. Obtaining exosomes from primary cells may be more difficult than from cell lines, therefore, generating NVs from primary cells as alternatives to exosomes would be more practicable for translation with high yield and simple production procedures. In this regard, Wu et al. firstly prepared NVs from primary hepatocytes of mice and reported that these NVs are competent to exosomes and can be used as a new option for tissue regeneration medicine [57]. Overall, for the most widely used method, serial extrusion of $10 \mu \mathrm{m}$, $5 \mu \mathrm{m}$ and $1 \mu \mathrm{m}$ followed by density gradient UC (DGUC), the protocol may be robust, but the yield of NVs compared to natural exosomes may vary significantly from different cell sources (from 8- to 150-fold).

Steps of extruding and the pore size of filters can be modified for generation of NVs. Choo et al. decreased the pore size of membrane filter to $1 \mu \mathrm{m}, 400 \mathrm{~nm}$ and $200 \mathrm{~nm}$ and obtained lipopolysaccharide (LPS)-treated RAW264.7 cells-derived NVs as M1NVs (M1 macrophage-derived NVs) [58]. They found that M1NVs could work as an immune regulator to repolarize M2 macrophages in tumors and potentiate the antitumor efficacy of anti-PD-L1. Injection of M1NVs shifted the polarization of microphage in tumors from pro-tumoral M1 type to anti-tumoral M2 type, improving the immune checkpoint therapy (Fig. 2). The substitute potential of NVs to exosomes for immunotherapy was also evaluated in another study with reduced extruding steps $(5 \mu \mathrm{m}$ and $1 \mu \mathrm{m})$. Zhu et al. evaluated the cytotoxicity of natural killer cell-derived NVs on cancer cells and reported that these NVs are potent immunotherapeutic agents for the treatment of cancer [59]. Also, extruding steps can be increased depending on the study purpose. We recently generated NVs from brain-derived endothelial cells using serial extruding method with increased steps $(10 \mu \mathrm{m}, 5 \mu \mathrm{m}, 1 \mu \mathrm{m}, 400 \mathrm{~nm}$ and $200 \mathrm{~nm})$ and reported the highest yield (500-fold) than natural exosomes [60]. Our head-to-head comparison study demonstrated NVs are potent alternative to exosomes for brain tumor nanomedicine.

In addition to serial extrusion using mini extruder, other strategies based on extruding mechanism have also been reported for NVs production. Fan et al. prepared macrophage-derived NVs by one-step nitrogendriven extruding of living cells through a $100-\mathrm{nm}$ filter [61]. NVs were purified and collected by UC. They show that NVs derived from M1 macrophages have selective tumor-killing effects and the effect can be enhanced by loading chemotherapeutics and constructing a specific miRNA-responded system. However, the yield of NVs by this method was not reported. In another study, Guo et al. enhanced the extruding method for NVs generation by magnetism [62]. They incubated cells with $10 \mathrm{~nm}$ iron oxide NPs (IONPs) for endosome encapsulation. Then, IONP-encapsulating endosomes were isolated by hypotonic treatment, homogenization and magnetic separation, followed by nanoporous membrane $(200 \mathrm{~nm})$ extrusion. NVs containing IONP were collected by magnetic separation. This method generated relatively pure endosome-derived NVs with very similar size, morphology and protein composition compared to natural small EVs. While the increase in yield is not very high (tenfold), NVs containing IONP can be easily collected without UC. In addition, those endosome-derived NVs can be loaded efficiently with chemotherapeutics by the ammonium sulfate gradient approach.

\section{Filtration-based method}

The extruding method is effective for NVs production but steps are less controllable as manual operation is required. Similar to the extruding method, the filtrationbased method can also be applied to produce NVs using serial membrane filters with different pore size. Protocols of the filtration-based method are more specific than manual extruding and require less manpower.

Jo et al. developed a mechanical device containing membrane filters for large-scale generation of NVs without UC [63]. In the device, cells are forced to pass through membrane pores (10 um and $5 \mathrm{um}$ ) by centrifugation. Cells are elongated, ruptured and assembled into NVs by centrifugal force. The NVs obtained by this device showed

(See figure on next page.)

Fig. 2 A typical top-down strategy for generating therapeutic macrophage derived-nanovesicles for tumor immunotherapy. M1 nanovesicles (M1NVs) were produced by serial extrusion of M1 macrophage induced by lipopolysaccharide (LPS). M1NV was purified by density gradient ultracentrifugation. M1NV reached the tumor site and polarized M2 tumor-associated macrophage (TAM) to anti-tumoral M1 type and induce secretion of pro-inflammatory cytokines to activate T cells. (Reprint with permission from [58]. Copyright American Chemical Society, 2018) 


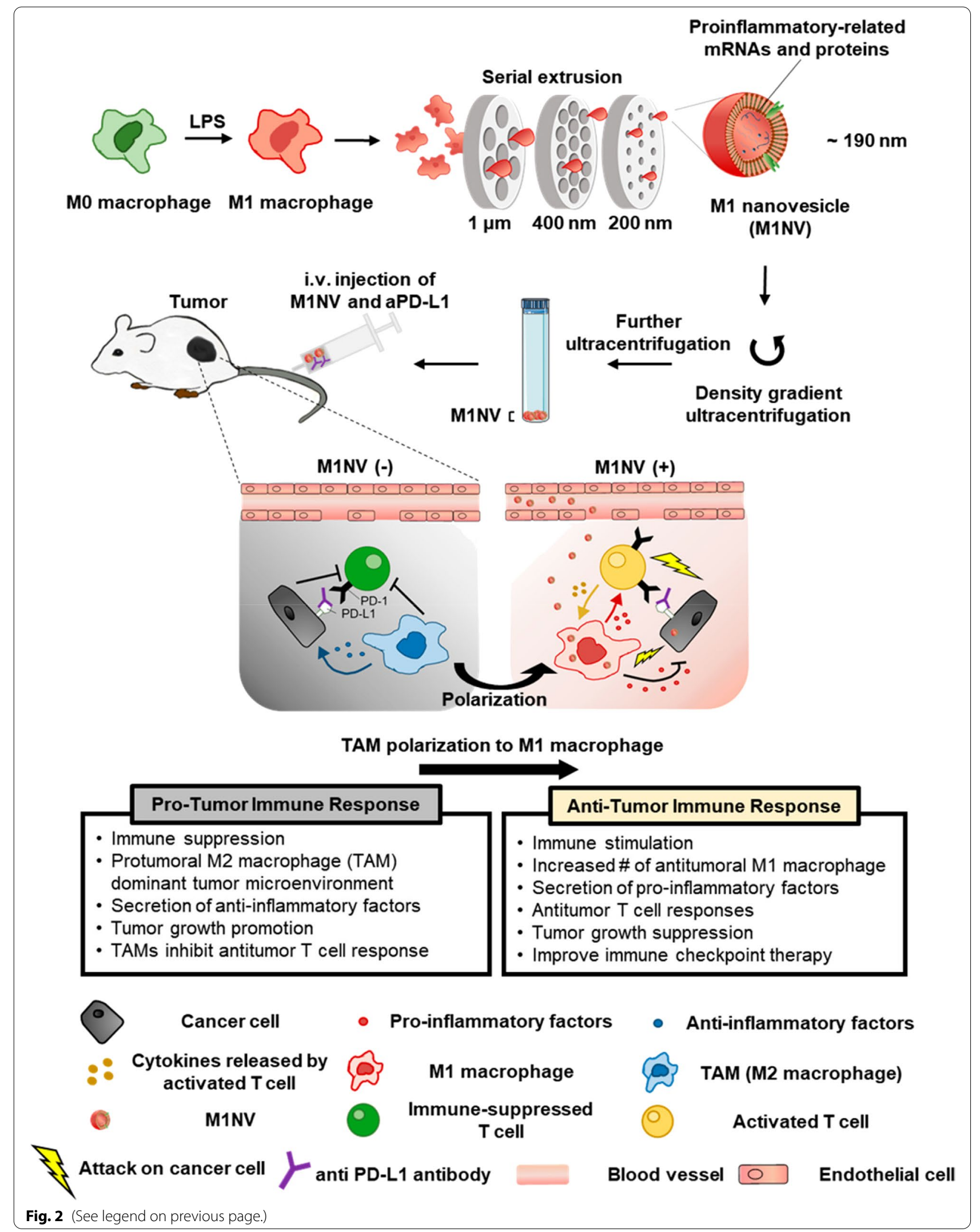


exosome-like structure and size distribution. While the membrane pores used in the device were relatively large, obtained NVs were small in diameters $(\sim 100 \mathrm{~nm})$. Also, they reported that NVs generated from murine embryonic stem cells by this method can transfer RNAs to target cells thus activating cellular signaling pathways. Further, Goh et al. simplified the device and reduced the production steps by using spin cups [64]. They obtained U937 cellsderived NVs using spin cups with two membrane filters $(10 \mu \mathrm{m}$ and $8 \mu \mathrm{m})$. Also, despite large membrane pores, the size of NVs was slightly larger than nature exosomes. NVs fabricated by the spin cup method showed similarity to exosomes in terms of physical characterization, protein and lipid components. But the yield is not very high (15fold). Besides, they observed higher targeting effects to tumors of NVs than natural exosomes, demonstrating NVs are ideal and alternative carriers to exosomes for tumor nanomedicine.

\section{Microfluidic device-based method}

Microfluidic technology is a multidisciplinary and advancing field [73]. Microfluidic devices consist of several micro components for manipulating tiny fluids. Microfluidic systems have many advantages in simplicity, automation and scalable fabrication [74]. Microfluidic systems have shown superiority in the detection, purification, fabrication and engineering of nano-sized materials such as liposomes [75] and exosomes [76].

In recent years, specific microfluidic systems have been developed for the mass production of NVs. Jo et al. used simple pressurization of living cells over a microfluidic device based on an array of parallel hydrophilic microchannels for the production of NVs [65]. Cells are stretched and broken into fragments by the shear stress. NVs are formed by self-assembling. This method efficiently generated NVs with exosome-like characteristics in terms of size, shape and biological contents. Moreover, NVs generated from embryonic stem cells by microfluidic fabrication showed the ability to transfer endogenous mRNA to target cell cultures. The NVs generated in that study exhibited the delivery ability very similar to natural exosomes. Further, this research group designed another microfluidic system for the fabrication of NVs by slicing living cells. Microchannels were lined with the silicon nitride $\left(\mathrm{Si}_{\mathrm{x}} \mathrm{N}_{\mathrm{y}}\right)$ microblade (500 nm in thickness) array and polydimethylsiloxane (PDMS) block [66]. Using a syringe pump, cells flowed through the microchannels and microblade that are perpendicularly aligned in the middle of the PDMS channel array, which sliced incoming cells into membrane fragments that were spontaneously self-assembled into NVs. These NVs can be loaded with exogenous materials for efficiently deliver to recipient cells. These two automatic microfluidic device-based methods showed higher yield (100-fold) than natural exosomes; nevertheless, both systems require UC step, which is identical to exosome purification.

\section{Nitrogen cavitation-based method}

In addition to manipulating living cells via extruding, filtration and microfluidic device, dead cells can also be used to obtain NVs. Gao et al. firstly reported that nitrogen cavitation can efficiently generate EVs-like NVs from neutrophils [67]. Activated neutrophils in suspension were filled in a nitrogen cavitation chamber and were physically disrupted by exposure to nitrogen cavitation at a pressure of $400-500$ psi at $0{ }^{\circ} \mathrm{C}$ for twice. Neutrophil-derived NVs in suspension were isolated by differential UC, followed by sonication. Neutrophil-derived NVs generated by the nitrogen cavitation method retained intact targeting molecules and can selectively bind inflamed vasculature to mitigate acute lung inflammation. Further, they reported that the NVs generated by nitrogen cavitation are similar to natural EVs after systematic comparison of size, morphology and protein markers [68]. However, the increase in yield (16-fold) of NVs by this nitrogen cavitation method is not very high compared to other top-down strategies.

\section{Sonication-based method}

Fragments of cell membranes may assemble to form small vesicles during sonication. Ghost NVs formed by cell membrane sheets without luminal components are also similar to exosomes. Go et al. broke cells with an alkaline solution and isolated membrane sheets by sonication to discard luminal cytosolic components [69]. Membrane pellets were obtained by UC. Drug-loaded NVs were generated by sonication-induced self-assembling. These NVs have uniformed size and similar physical features compared to natural exosomes but have significantly higher (200-fold) yield. Besides, these NVs can efficiently deliver dexamethasone to endothelial cells to mitigate the systemic inflammatory response induced by gram-negative bacterial outer membrane vesicles.

\section{Cell bleb-based method}

As for above mentioned top-down strategies, cells are sacrificed by physical force. That means the production of NVs is non-recyclable, limiting the production efficiency. Hence, the generation of natural NVs without sacrificing cells would be an advanced top-down strategy. It would be interesting if mass production of NVs could be achieved without disrupting cells.

A bleb phenomenon has been observed when the cell membrane is exposed to a sulfhydryl-blocking reagent [77]. Despite considerable quantity, sulfhydryl-blocking often induces giant membrane vesicles with high heterologous size distribution that was not suitable for drug 
delivery. Ingato et al. optimized this sulfhydryl-blocking method by adding paraformaldehyde and dithiothreitol, a disulfide-reducing agent, to cells during culturing [70]. This improved method increased the secretion of natural NVs with a much smaller size $(30 \mathrm{~nm})$ after filtration centrifugation. They reported that NVs induced by sulfhydryl-blocking are solely the product of cell membrane blebbing, resulting in high homogeneity. NVs preserved cell membrane components and contain cytoplasmic contents, allowing facile engineering by directly modifying the donor cells. Besides, natural NVs-mediated delivery of doxorubicin (DOX) effectively and safely suppressed tumor growth in a murine tumor model. This strategy showed various advantages in sustainable and massive production, size control, low cost, feasibility and stability.

\section{Bottom-up strategies}

By contrast, bottom-up strategies refer to manufacturing approaches that begin with small molecules as the building block to form large and complex structures through a stepwise assembling process combining their physical and chemical properties. A typical example of the bottom-up strategy in the drug delivery system field is liposome, which is a lipid-based NP designed to mimic the bilayer structure of cell membrane [78, 79]. Also, as natural exosomes share a similar membrane structure to cells, liposomes hold great promise to resemble exosomes [80]. To mimic the structure of natural exosomes, specific lipids, from classical formulations to simulating the composition of exosomes, are used to form lipid bilayer and then modified with chemical groups or engineered with surface proteins. Therefore, bottom-up strategies require a deep understanding of the functions of key components of natural exosomes. By assembling desired components learned from natural exosomes, artificial exosomes can be clean in composition and have controllable characteristics. Therefore, from an industrial view, fully artificial exosomes may have higher pharmaceutical acceptability and would be more suitable for production and in concordance with regulation. In addition, one of the most widely used method for liposome preparation is the thin layer evaporation (TLE) method. Lipids are firstly dissolved in organic solutions. By evaporating the solution, lipids could form a thin layer in the flask. Lipid suspension can be obtained by adding water (hydration) to the lipid thin layer. Extruding the lipid suspension through membrane pores will produce liposomes with controlled size distribution. During the TLE process, drugs in a solution can be incorporated into liposomes during hydration, leading to a more efficient drug loading for artificial exosomes than pre or post-loading drugs into NVs or exosomes [81]. Several bottom-up approaches to fabricate artificial exosomes start from synthetic materials have been summarized (Table 2).

\section{Liposomes conjugated with specific peptide}

Conjugating liposomes with peptide is a simple way to develop artificial exosomes; however, which peptide to be conjugated is dependent on what kind of bioactivity is supposed to have in artificial exosomes. Classical liposomes coupled with synthetic MHC Class I/peptide complexes as artificial exosomes could mimic functions of exosomes [82]. Specifically, MHC/peptide complexes and $\mathrm{Fab}$ regions were incubated with Traut's reagent for binding to maleimide lipids. After removing excess Traut's reagent by using a desalting column, activated $\mathrm{MHC} /$ peptide complexes and Fab regions were incubated with liposomes, followed by chromatography and ultrafiltration for purification. These artificial exosomes showed similar size to natural exosomes and effectively targeted to $\mathrm{T}$ cells and worked semi-directly to activate and expand T cells. Similarly, Martinez-Lostao et al. generated liposomes with a size and lipid composition resembling natural exosomes [83]. APO2L/TRAIL was conjugated with liposomes. The resulting artificial exosomes showed considerable therapeutic effects on antigen-induced arthritis in rabbits. Similarly, in another study, the same formulation of liposomes was used and conjugated with Apo2L/TRAIL with improved activity [84]. These artificial exosomes successfully overcame the chemo-resistance of human hematologic tumor cells. For liposomes conjugated with peptides, the key might be the activity of the peptide, while liposomes worked mostly as a carrier.

\section{Liposomes coupled with specific antibody}

Similar to conjugating liposome with peptide, liposome coupled with antibody may also exert bioactivity mostly for the specific antibody. To mimic the function of exosomes and target dendritic cells (DCs) to activate immune, $\mathrm{Li}$ et al. utilized DC-Chol, 3-(N-(N0, N0-dimethylaminoethane)carbamoyl)Cholesterol, to provide positive charge and developed cationic nanoliposomes by micro-emulsion and micelle assembling [85]. DEC205 monoclonal antibody was anchored to nanoliposomes via reactions of amine group of DEC205 and ester, activated by adding 1-(3-Dimethylaminopropyl)3-ethylcarbodiimide hydrochloride (EDC) and $\mathrm{N}$-Hydro xysuc cinimid (NHS), of the nanoliposomes. This strategy provided an efficient approach to prepare artificial biomimetic exosomes to develop antigen carriers for specific DCs targeting and antigen presentation to induce immune responses. 


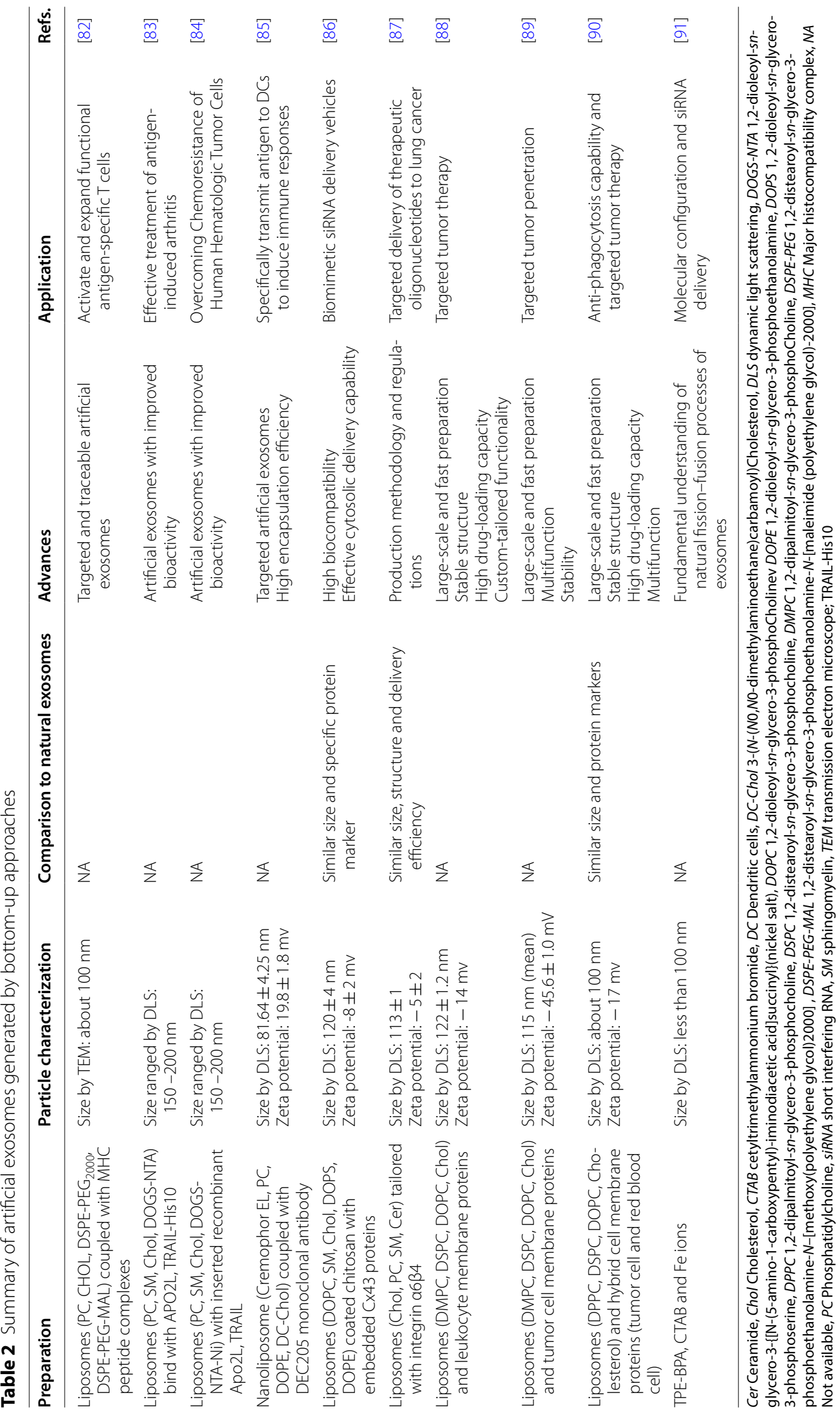




\section{NPs embedded with specific protein}

In addition to mimic the functions of exosomes to activate molecular pathways, liposome-based artificial exosomes can also be used for drug or gene delivery. To develop EM NPs for siRNA delivery, Lu et al. constructed liposomes coated chitosan NPs as exosome-mimicking membranes to protect siRNA cargo and introduced to synthesized plasmids encoding connexin 43 (Cx43), a transmembrane protein, to direct the transcription, translation, and integration of $\mathrm{Cx} 43$ in the lipid layers in EM [86]. Integrated Cx43 worked functionally in cellular transport and facilitated the delivery of siRNA in EM to Cx43-expressing U87 MG cells. The EM exhibited high siRNA delivery efficiency and biocompatibility. Despite limited delivery efficiency than commercial transfection Lipo 2000 reagent, that strategy formulated EM using a cell-free protein synthetic approach and advanced the development of artificial exosomes as biomimetic nanocarriers.

In another study, Vázquez-Ríos et al. developed EM nanosystems that simulate exosomal structure and functions for targeted drug delivery to lung adenocarcinoma cells [87]. Liposomes were loaded with therapeutic oligonucleotides and then tailored with integrin $\alpha 6 \beta 4$ for lung organotropism. The EM showed great similarities to natural exosomes from physicochemical and pharmaceutical aspects. The EM exhibited similar lung targeting and delivery efficiency to tumor-derived exosomes. Importantly, this strategy provided important advantages in terms of production methodology and regulations. Still, for liposomes modified with a specific protein, the protein is vital for simulating the functions of natural exosomes.

\section{Liposomes modified with membrane proteins}

Modification of specific proteins on liposomes may endow desired functions such as enhanced cellular uptake and targeting effects, but it may be inadequate to resemble the complex functions of natural exosomes. Proteomic study revealed thousands of functional proteins in exosomes [55], indicating impossibility to perform engineering modification repeatedly. A feasible approach would be integrating a group of proteins with one step.

It has been reported that leukocytes freely circulate in the bloodstream and selectively target the inflamed vasculature in response to injury, infection, and tumorigenesis [92]. Leukocyte-derived NVs can evade the mononuclear phagocytic system and are able to across the endothelial vessel [93]. Molinaro et al. extracted membrane proteins from circulating leukocytes in the blood and developed leukocyte-mimicking biomimetic liposomes, called leukosomes, by incorporating membrane proteins in lipid vesicles [88]. Membrane proteins from leukocyte possess cellular adhesion molecule ligation, such as lymphocyte function-associated antigen 1, macrophage-1 antigen, and P-selectin glycoprotein ligand-1, etc., facilitating the delivery of DOX to both tumor-associated vasculature and parenchyma, which might be difficult for specific protein modification. Chemotherapeutic-loaded leukosomes could be used for targeted tumor therapy with potent anti-cancer activity. That study demonstrated the versatility of liposomes modified with membrane proteins as artificial exosomes for biomedical applications. Recently, we also generated biomimetic liposomes by incorporating cancer cell membrane proteins into synthetic liposomes and enhanced the tumor targeting ability [89]. Further, elastase was bound to biomimetic liposome through charge-mediated interaction. Biomimetic liposomes with surface bound elastase degraded tumor stroma and facilitated tumor penetration of chemotherapeutics and cytotoxic $\mathrm{T}$ lymphocytes.

In addition to membrane proteins from specific cell types, membrane proteins from different cells could also be simultaneously used to modified liposomes, depending on desired functions, as hybrid artificial exosomes. Zhang et al. used hybrid membrane proteins strategy and developed protein chimeric liposomes as artificial chimeric exosomes (ACEs), combining anti-phagocytosis properties from red blood cell (RBC) membrane proteins and tumor targeting abilities from homologous tumor cell membrane proteins [90]. More specifically, the antiphagocytosis capability was from the high level of CD47 in membrane proteins of RBCs while tumor targeting and adhesion abilities were from EpCAM, Galectin 3 and N Cadherin in membrane proteins of cancer cells (Fig. 3). That strategy demonstrated that hybrid membrane proteins are useful for developing multifunctional artificial exosomes.

\section{Fully synthetic EM without proteins}

The investigation of the fission (releasing) and fusion (swallowing) processes of exosomes are important for the understanding of intercellular transport and signaling. However, manipulating natural exosomes has been challenging due to natural complexity in composition and cellular environment. In this regard, Li et al. developed supramolecular vesicles consisted of aggregation-induced emission active molecule TPE-BPA and cetyltrimethylammonium bromide (CTAB) [91]. The TPE-BPA@8CTAB vesicles are capable of coordination with metal ions such as $\mathrm{Fe}^{2+}$ and $\mathrm{Fe}^{3+}$. While the vesicles have no protein component, they can fuse together and form large-sized vesicles upon oxidation, undergo a fission process and then return to small-sized vesicles 


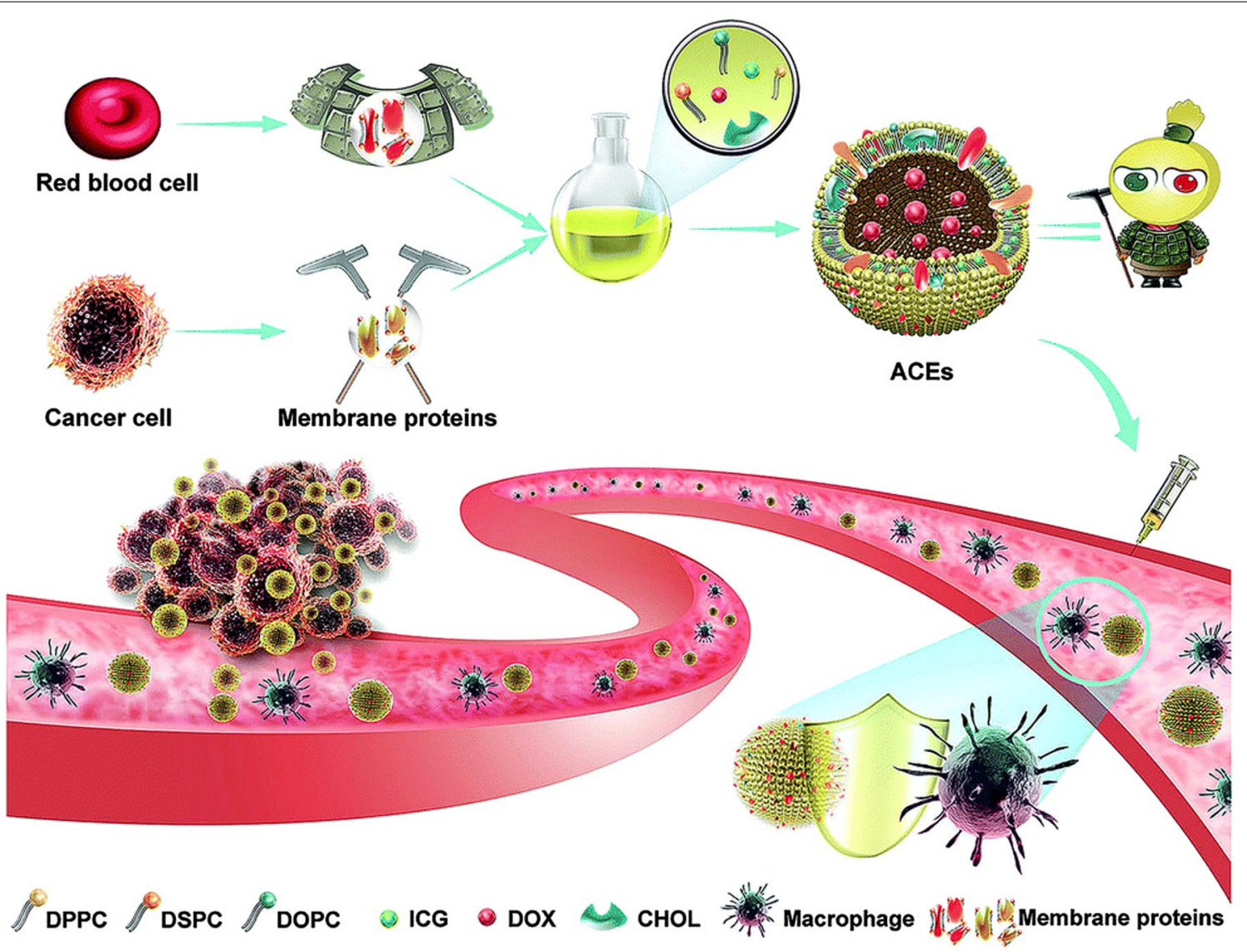

Fig. 3 A typical bottom-up strategy for generating fully artificial exosomes for drug delivery. Hybrid membrane proteins from red blood cells and cancer cells were integrated into liposomes during preparation to form artificial chimeric exosomes (ACEs). ACEs have anti-phagocytosis ability during circulation (from red blood cell) and the tumor-homing ability (from cancer cell) for targeted drug delivery. (Reprinted with permission from Ref. [90]Copyright Royal Society of Chemistry, 2019)

through reduction, mimicking the fusion and fission behaviors of exosomes. The aggregation-induced emission (AIE) feature from TPE-BPA of the EM enabled monitoring of vesicular transformation by fluorescence emission changes [94], thus providing innovative understanding for the fusion and fission behaviors of exosomes, especially for cargo release. Besides, the EM may be a candidate for drug delivery as it can release siRNA through the fusion process. While this supramolecular vesicle may not be competitive for drug delivery compared to other artificial exosomes for the lack of protein components, this type of EM may serve as a useful tool for innovative understanding of exosome behaviors.

\section{Biohybrid strategies}

In addition to top-down and bottom-up strategies, biohybrid is another technique that has been used for developing EMs by merging synthetic NPs and natural vesicles. Biohybrid is an emerging field and these hybrid vesicles are designed specifically for application in advanced drug delivery with optimized performance. EM by biohybrid strategies is semi-artificial with the advantages of synthetic materials including production, controlling, engineering, drug loading and stability and properties of endogenous exosomes such as tropism, biological barrier penetration, long circulation, low immunogenicity and high biocompatibility. A number of studies have developed hybrid of nanomaterials and natural vesicles, mostly by fusion exosomes with liposomes, while the fusion process may be achieved by different techniques (Table 3).

\section{Biohybrid by freeze-thawing}

Despite tropism of exosomes, the membrane engineering may be necessary for advanced drug delivery [102]. To increase colloidal stability and blood circulation of exosomes by optimizing the surface, Sato et al. applied a facile membrane-engineering strategy using direct membrane fusion between synthetic liposomes and purified exosomes [95]. To induce the fusion of exosome and liposome membranes the authors used a freeze-thaw 


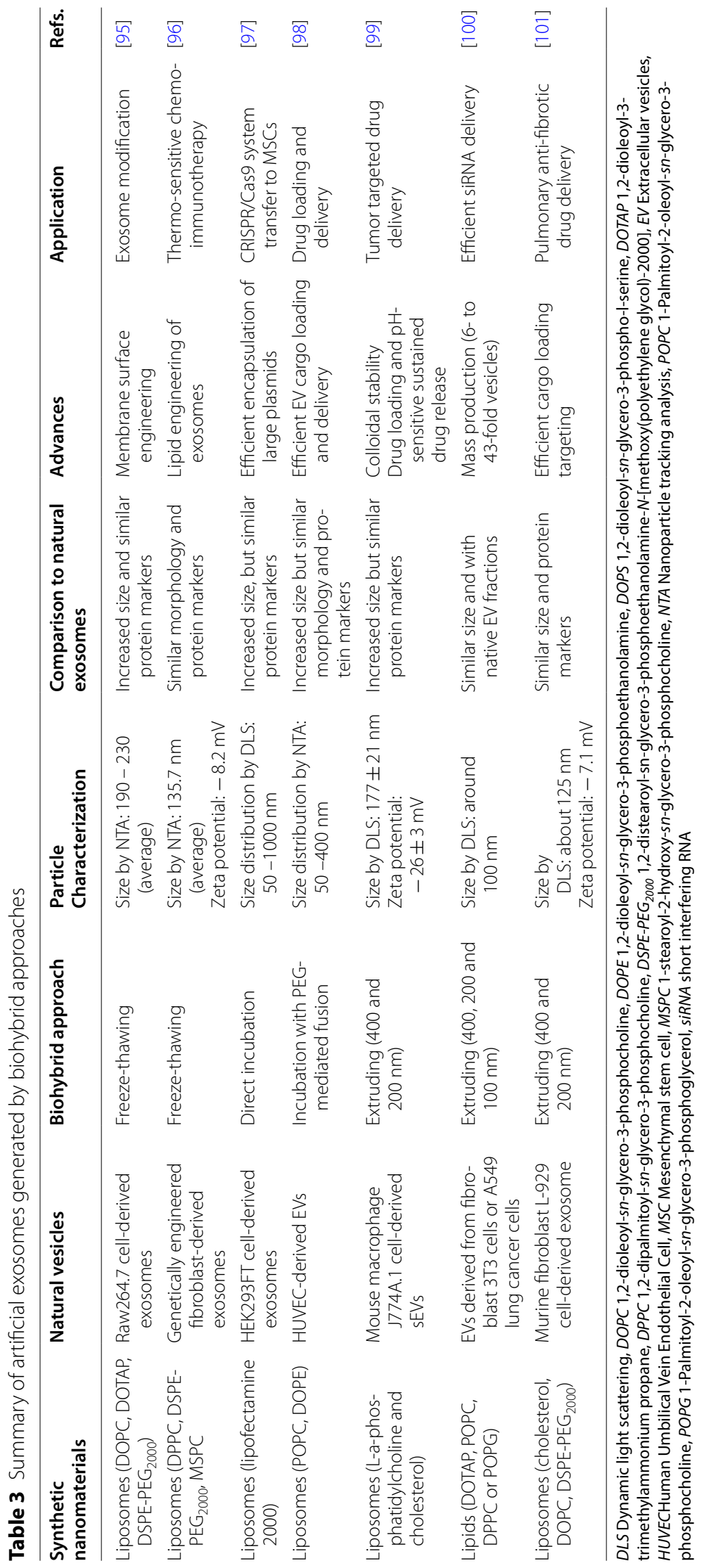




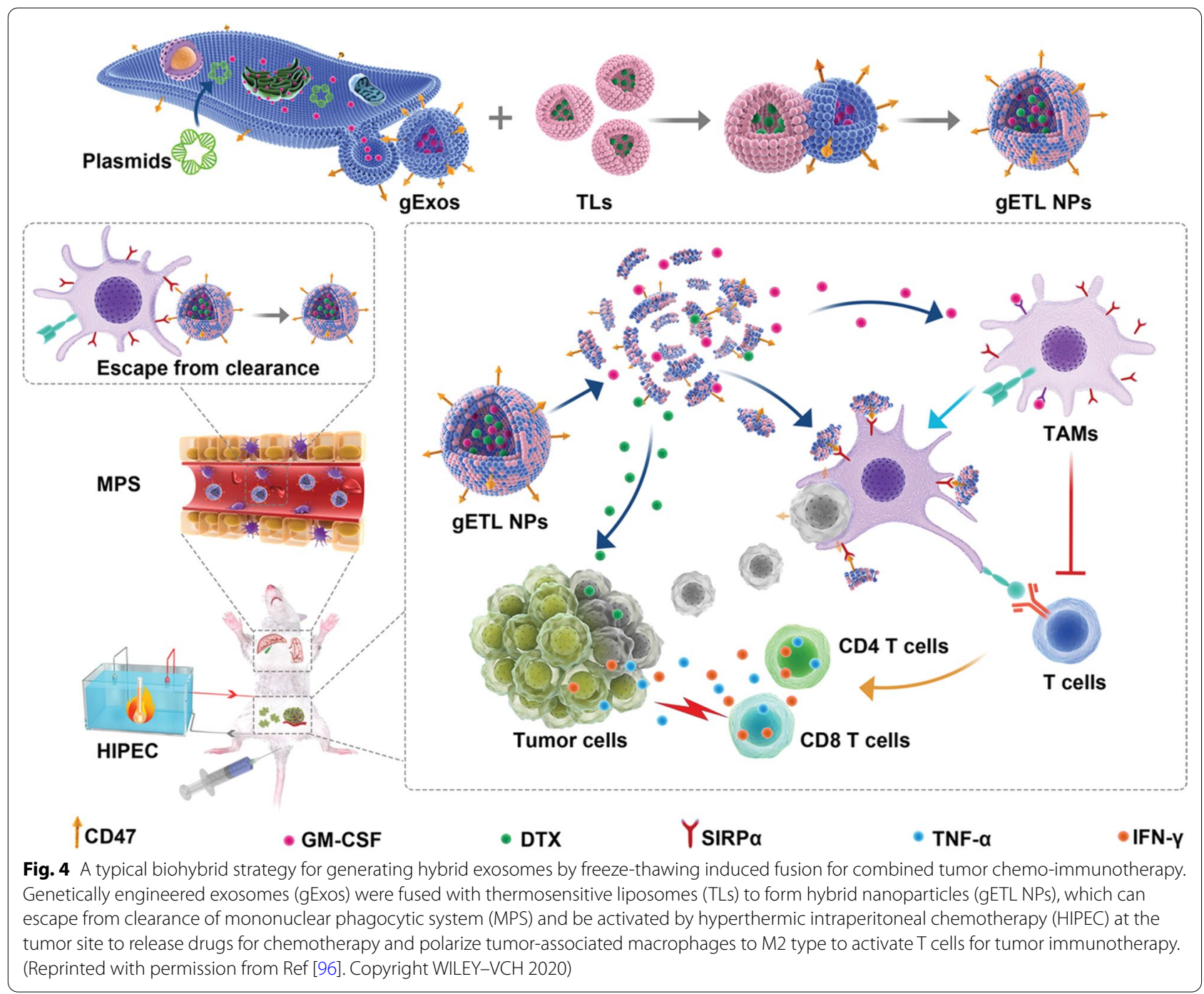

method previously developed for liposome engineering. Exosome-liposome mixture was subjected to liquid nitrogen and thawed at room temperature for several cycles. The mean size was increased and protein components were diluted after fusion. The exosomes-liposomes hybrid, as advanced drug delivery systems, showed increased cellular uptake than liposomes and can transport exogenous hydrophobic lipids from liposomes and hydrophilic cargoes from exosomes to recipient cells.

Synthetic liposomes can be multifunctional such as $\mathrm{pH}$-sensitive [103], photo-sensitive [104] and thermosensitive [105] by incorporating specific lipids liposomes. Fusion multifunctional liposomes with natural vesicles would be a feasible approach for endowing exosomes with enhanced delivery properties and developing multifunctional hybrid. Lv et al. generated hybrid NPs of genetically engineered fibroblasts-derived exosomes expressing CD47 and thermosensitive liposomes following freeze-thaw procedures [96]. The hybrid NPs are slightly large in size but have similar morphology to exosomes and retained most protein markers of exosomes. Importantly, the hybrid NPs showed improved circulation and preferential accumulation in tumors and released drugs in response to temperatures. Genetically engineered thermosensitive liposome-exosome hybrid can escape mononuclear phagocytic system and target the tumor site, in which hyperthermia therapy stimulates the hybrid and induces combined immune-chemotherapy (Fig. 4).

\section{Biohybrid by incubation}

Incubation is a mild and commonly used method for various cellular processes and reactions. Fusion of liposomes and exosomes may occur during incubation as their membranes both have lipid bilayer structure. Incubation-induced spontaneous fusion may result in wide size 
distribution of hybrid particles with a high polydispersity index (PDI). The impact of incubation conditions on the fusion process requires further investigation.

Exosomes are promising targeted delivery nanocarrier, but have limited efficiency, for their small size, in encapsulating exogenous large nucleic acids, such as CRISPR/ Cas9 System. The fusion of exosomes and liposomes may achieve efficient loading of large plasmids into the hybrid. Lin et al. developed a hybrid NP by simple incubation of HEK293FT cell-derived exosomes with CRISPR/Cas9 expressing liposomes at $37^{\circ} \mathrm{C}$ for $12 \mathrm{~h}$ [97]. The hybrid NPs delivered the CRISPR/Cas9 system to mesenchymal stem cells (MSCs) and achieved gene editing by expressing the encapsulated genes in the MSCs, which cannot be transfected by the liposome alone. Taken together, the exosome-liposome hybrid NPs can deliver CRISPRCas9 system in MSCs, providing a promising tool for targeted gene editing.

The incubation-induced fusion of exosomes and liposomes can be enhanced by mediators on the surface, such as PEG. Piffoux et al. modified the EVs by incubation with liposomes via PEG-mediated fusion [98]. PEGmediated fusion was proved to be an efficient approach to engineer EVs with exogenous compounds while preserving their inherent contents. Moreover, this fusion method enabled bioengineering of liposomal particles with biogenic molecules; importantly, the PEG-mediated fusion strategy allows efficient loading of cargoes and the feasible engineering of EV membranes with adaptable functions.

\section{Biohybrid by co-extruding}

Another reported method for generating biohybrid of exosomes and liposomes is co-extrusion. Under physical stress, membranes of exosomes and liposomes would break and re-assemble to form hybrid vesicles when passing through the membrane pore with controlled size. Exosomes have been explored as a drug delivery candidate owing to their natural functionalities. However, it has been reported that exosomes obtained by different method may differ in yield and purity [47]. Unlike freezethawing and incubation biohybrid methods, which are spontaneous, the co-extruding method has advantages in controlling the product hybrid vesicles.

Liposomes have pharmaceutical flexibility for engineering and modification for preparing functional carriers but lack endogenous functionality compared to natural vesicles. Rayamajhi et al. hypothesized that macrophage-derived sEVs possess tumor-targeting properties for targeted drug delivery [99]. Macrophage J774A.1 cell-derived sEVs $(139 \mathrm{~nm})$ and synthetic liposomes $(131 \mathrm{~nm})$ at the ratio of 1:5 were mixed, vortexed, sonicated and extruded through polycarbonate membrane filters (400 and $200 \mathrm{~nm}$ ). The hybrid vesicles showed a slightly larger size $(177 \mathrm{~nm})$ than precursors but have a more uniformed size distribution (PDI: 0.19) than sEVs (PDI: 0.25). Advantages of the two types of nanocarriers were merged as efficient hybrid delivery systems.

The low yield of EV by natural secretion limits its mass production and potential for clinical applications. Engineering EVs by introducing exogenous lipids can tune their surface composition and functionality and increase their production without affecting intrinsic targeting and delivery properties. For membrane engineering of EVs, the synthetic lipid can be directly used for co-extruding with EVs without liposome formation. Jhan et al. mixed EVs with suspension of synthetic lipids and serially extruded through membranes (400, 200 and $100 \mathrm{~nm}$ ) to form lamellar vesicles with controlled size [100]. This method increased the number of vesicles by 6 to 43 -fold than isolated EVs. Also, exogenous siRNA was successfully loaded into hybrid vesicles that retained improved cellular uptake to recipient cells and achieved an effective gene silencing effect comparable to commercial Lipofectamine RNAiMax. Doping synthetic lipids in membranes of natural EVs is a convenient approach for maximizing the delivery potentials with increased particle quantities.

More recently, the delivery potentials of hybrid of exosomes and liposomes were assessed in vivo for targeted pulmonary fibrosis therapy, which has been challenging in the clinic for insufficient drug concentration and poor targeting. Sun et al. developed a clodronate (CLD)-loaded hybrid drug delivery system, consisted of liposome and fibroblast-derived exosomes with properties preventing phagocytosis and targeting fibroblast, for the treatment of pulmonary fibrosis [101]. The HEs efficiently accumulated in the fibrotic lesion and exhibited significant penetration of pulmonary fibrotic tissue for the improved affinity for fibroblasts by homologous exosome.

\section{Comparison of natural exosomes and artificial exosomes}

Along with the rapid growth in nanobiotechnology, the research of exosomes has been advancing from biology $[32,106]$ to biomarkers $[107,108]$ and nanomedicines [109] over the past decade. For drug delivery, exosomes have shown various advantages compared with conventional synthetic materials such as liposomes [110]. The therapeutic potential of exosomes-mediated drug delivery are still in tests of preliminary clinical trials (pancreatic cancer: NCT03608631; acute ischemic stroke: NCT03384433; colon cancer: NCT01294072), while the efficacy of cell-derived exosome-like vesicles has been evidenced in several pilot trials [111-113]. Nevertheless, 
Table 4 Comparison of natural exosomes and different types of artificial exosomes for translational nanomedicine

\begin{tabular}{|c|c|c|c|c|c|c|c|c|}
\hline Types & Source & Scalability & Procedures & Time-cost & Manpower & Sustainability & Characterization & Applicability \\
\hline Natural exosomes & Cell supernatant & $\star^{a}$ & $\psi^{2} \boldsymbol{x}^{\mathrm{b}}$ & 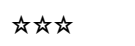 & 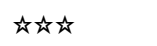 & $\star \star$ & $\star$ & $\star \star$ \\
\hline $\begin{array}{l}\text { Artificial exosomes } \\
\text { (top-down } \\
\text { approach) }\end{array}$ & Cells & $\star \star$ & 论放 & 论谈 & 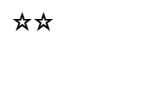 & $\star$ & $\star$ & $\star \star \star$ \\
\hline $\begin{array}{l}\text { Artificial exosomes } \\
\text { (bottom-up } \\
\text { approach) }\end{array}$ & Synthetic materials & $\star \star \star$ & 论场 & 柁 & 论 & $\star \star \star$ & $\star \star$ & $\star$ \\
\hline $\begin{array}{l}\text { Artificial exosomes } \\
\text { (biohybrid } \\
\text { approach) }\end{array}$ & $\begin{array}{l}\text { Synthetic materials } \\
\text { and cell super- } \\
\text { natant }\end{array}$ & $\star$ & 论败访 & 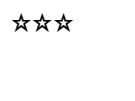 & 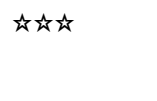 & $\star \star$ & $\star$ & $\star \star \star$ \\
\hline
\end{tabular}

${ }^{\text {a }}$ is to indicate that the aspect is favourable

${ }^{b}{ }_{k}$ is to indicate that the aspect is unfavorable

clinical translation of natural exosomes has been challenging [114]. Major hurdles including large-scale production, standard purification protocols, characterization of complex composition, cargo loading, quality control and storage stability are in their way to products for therapeutic applications [115]. Mass production of exosomes may be achieved through the development of bioreactors [38]; however, as biological components, their standardized and reproducible production requires comprehensive control of genetic stability and culturing condition of producing cells; purification requires subtype identification and quantification of contaminants [116]; efficacy is dependent on drug loading efficiency and capacity [117]; storage of therapeutic exosomes is supposed to have high recovery without damage to exosome particles as well as their biological contents $[118,119]$. From a current perspective, the development of exosomes for therapeutic drug delivery is still in infancy and the cost for translational research and clinical application would be very high.

In recent years, artificial exosomes have been developed with higher pharmaceutical acceptability to overcome the drawbacks of natural exosomes as new theranostic biomaterials for potential clinical applications [45]. However, there are some challenges for different strategies developing artificial exosomes for the following aspects: yield, procedures, time-cost, manpower, sustainability, characterization and efficacy, which are summarized and compared to natural exosomes (Table 4).

Top-down strategy is the most widely reported method for obtaining artificial exosomes. One major strength of the top-down strategy is the applicability because NVs are fully biological and have similar physiochemical and biological features to natural exosomes. Similar to natural exosomes, the yield of artificial exosomes by top-down strategies may vary from cell to cell. For the serial extruding method, most studies reported a nearly 100 -fold higher yield than natural exosomes, but higher yields have also been reported and the maximum was 500fold (Table 1). Compared to natural exosomes, preparation of artificial exosomes by top-down strategies could be cumbersome as UC-based purification procedures are still required following serial extruding or nitrogen cavitation. The development of specific devices may simplify the procedures and increase production efficiency and reduce time-cost and manpower [63]. However, for generating NVs, cells are sacrificed and broken into fragments, leading to limited production sustainability. Also, it has not been raised whether natural exosomes in cells should be considered as contaminants that may influence the characterization of NVs.

Bottom-up strategies are able to produce "clean" artificial exosomes with determined formulations and have the highest scalability because synthetic materials could be feasibly obtained and used for massive production. Besides, the cost of time and manpower could be remarkably reduced by using synthetic materials. Multiple modifications of liposomes are still challenging for complex procedures, uncertain conditions and instability. Another major drawback of bottom-up approaches for generating liposome-based artificial exosomes is that synthetic materials can still hardly mimic the complex composition of natural exosomes. Therefore, the functions of natural exosomes can hardly be fully reproduced by artificial exosomes based on bottom-up strategies. Publications that have compared artificial exosomes with natural exosomes are scarce. Most studies only evaluated physicochemical and biological properties of artificial exosomes (Table 2). A previous study reported a preliminary comparison concerning drug delivery efficiency [87]. Currently, preparing artificial exosomes that fully assembles components of natural exosomes may be pharmaceutically impossible [64], modification of liposomes with key proteins 
is dependent on the purpose and may not be consistent with natural exosomes. Therefore, the translational applicability of bottom-up strategies is limited.

Biohybrid approaches can only produce semi-artificial exosomes. The yield of artificial exosomes by biohybrid strategies would not be very high as natural exosomes are still required. In addition, the involvement of natural vesicles may face methodological challenges similar to natural exosomes. Preparation of biohybrid exosomes could be laborious as preparation of synthetic liposomes and isolation of natural vesicles are both required. Characterization of hybrid particles may be influenced by additional liposomes and exosomes and the purification would be rather difficult as liposomes, exosomes and the hybrid are very similar in multiple aspects. However, one strength of the biohybrid approach is that the hybrid possesses natural components from exosomes, despite dilution, those hybrid nanocarriers may have improved delivery efficiency than liposomes and higher stability than exosomes, leading to high applicability. Besides, the fusion method that is widely used in biohybrid strategies provided a feasible option for drug loading such as loading biological cargoes into liposomes and loading exogenous therapeutic agents into exosomes [98].

\section{Concluding remarks}

Biomimetic nanocarriers are the next generation of drug delivery systems in nanomedicine for improving health. Advancements in nanobiotechnology provide avenues for the development of artificial exosomes that may accelerate clinical translation for nanomedicine application. Currently, natural exosomes are just in their preliminary clinical trials and artificial exosomes are not yet ready for translation. Major challenges include the preparation protocols, characterization and biocompatibility concerns. Artificial exosomes have commercial advantages for their up-scale productivity. In the future, novel and multifunctional artificial exosomes will be developed, with contributions from multidiscipline efforts of biotechnology, nanotechnology, chemical engineering and pharmaceutical industry, to improve healthcare. We hold confidence for artificial exosomes' potentials for personalized nanomedicine.

\section{Acknowledgements}

Not applicable.

\section{Authors' contributions}

YJL and DXX defined the focus of the review. YJL and JYW summarized studies. YJL drafted the manuscript. All authors reviewed the final version of the manuscript. All authors read and approved the final manuscript.

\section{Funding}

The work was supported by the Hunan Provincial Science and Technology Plan (No. 2016TP2002).

\section{Declarations}

Ethics approval and consent to participate Not applicable.

\section{Competing interests}

No potential conflict of interest was reported by the authors.

\section{Author details}

'Department of Pharmacy, The Second Xiangya Hospital, Central South University, 139 Middle Renmin Road, Changsha 410011, China. ${ }^{2}$ Hunan Provincial Engineering Research Centre of Translational Medicine and Innovative Drug, Changsha, China. ${ }^{3}$ Institute of Clinical Pharmacy, Central South University, Changsha, China.

Received: 11 June 2021 Accepted: 4 August 2021

Published online: 12 August 2021

\section{References}

1. Crommelin DJA, van Hoogevest P, Storm G. The role of liposomes in clinical nanomedicine development. What now? Now what? J Control Release. 2020;318:256-63.

2. Cabral H, Miyata K, Osada K, Kataoka K. Block copolymer micelles in nanomedicine applications. Chem Rev. 2018;1 18:6844-92.

3. Yamamoto K, Imaoka T, Tanabe M, Kambe T. New horizon of nanoparticle and cluster catalysis with dendrimers. Chem Rev. 2020;120:1397-437.

4. Deng S, Gigliobianco MR, Censi R, Di Martino P. Polymeric nanocapsules as nanotechnological alternative for drug delivery system: current status, Challenges and Opportunities. Nanomaterials (Basel). 2020;10:847.

5. Lai H, Stenzel MH, Xiao P. Surface engineering and applications of nanodiamonds in cancer treatment and imaging. Int Mater Rev. 2020;65:189-225.

6. Allahyari S, Trotta F, Valizadeh H, Jelvehgari M, Zakeri-Milani P. Cyclodextrin-based nanosponges as promising carriers for active agents. Expert Opin Drug Deliv. 2019;16:467-79.

7. Elzayat A, Adam-Cervera I, Alvarez-Bermudez O, Munoz-Espi R. Nanoemulsions for synthesis of biomedical nanocarriers. Colloids Surf B Biointerfaces. 2021;203:111764.

8. Wang TT, Xia YY, Gao JQ, Xu DH, Han M. Recent progress in the design and medical application of in situ self-assembled polypeptide materials. Pharmaceutics. 2021;13:753

9. Manzari MT, Shamay Y, Kiguchi H, Rosen N, Scaltriti M, Heller DA. Targeted drug delivery strategies for precision medicines. Nat Rev Mater. 2021;6:1-20.

10. O'Brien ME, Wigler N, Inbar M, Rosso R, Grischke E, Santoro A, Catane R, Kieback DG, Tomczak P, Ackland SP, et al. Reduced cardiotoxicity and comparable efficacy in a phase III trial of pegylated liposomal doxorubicin $\mathrm{HCl}$ (CAELYX/Doxil) versus conventional doxorubicin for first-line treatment of metastatic breast cancer. Ann Oncol. 2004;15:440-9.

11. Northfelt DW, Dezube BJ, Thommes JA, Miller BJ, Fischl MA, FriedmanKien A, Kaplan LD, Du Mond C, Mamelok RD, Henry DH. Pegylatedliposomal doxorubicin versus doxorubicin, bleomycin, and vincristine in the treatment of AIDS-related Kaposi's sarcoma: results of a randomized phase III clinical trial. J Clin Oncol. 1998;16:2445-51.

12. Gordon AN, Fleagle JT, Guthrie D, Parkin DE, Gore ME, Lacave AJ. Recurrent epithelial ovarian carcinoma: a randomized phase III study of pegylated liposomal doxorubicin versus topotecan. J Clin Oncol. 2001;19:3312-22.

13. Meazza C, Asaftei SD. State-of-the-art, approved therapeutics for the pharmacological management of osteosarcoma. Expert Opin Pharmacother. 2021. https://doi.org/10.1080/14656566.2021.1936499.

14. Koudelka S, Turanek J. Liposomal paclitaxel formulations. J Control Release. 2012;163:322-34

15. Von Hoff DD, Ervin T, Arena FP, Chiorean EG, Infante J, Moore M, Seay T, Tjulandin SA, Ma WW, Saleh MN, et al. Increased survival in pancreatic cancer with nab-paclitaxel plus gemcitabine. N Engl J Med. 2013;369:1691-703. 
16. Goldstein D, El-Maraghi RH, Hammel P, Heinemann V, Kunzmann V, Sastr J, Scheithauer W, Siena S, Tabernero J, Teixeira L, et al. nab-Paclitaxel plus gemcitabine for metastatic pancreatic cancer: long-term survival from a phase III trial. J Natl Cancer Inst. 2015. https://doi.org/ 10.1093/jnci/dju413.

17. Gradishar WJ, Tjulandin S, Davidson N, Shaw H, Desai N, Bhar P, Hawkins M, O'Shaughnessy J. Phase III trial of nanoparticle albumin-bound paclitaxel compared with polyethylated castor oil-based paclitaxel in women with breast cancer. J Clin Oncol. 2005:23:7794-803.

18. Socinski MA, Bondarenko I, Karaseva NA, Makhson AM, Vynnychenko I, Okamoto I, Hon JK, Hirsh V, Bhar P, Zhang H, et al. Weekly nab-paclitaxel in combination with carboplatin versus solvent-based paclitaxel plus carboplatin as first-line therapy in patients with advanced non-small-cell lung cancer: final results of a phase III trial. J Clin Oncol. 2012;30:2055-62.

19. Blanco E, Shen H, Ferrari M. Principles of nanoparticle design for overcoming biological barriers to drug delivery. Nat Biotechnol. 2015;33:941-51.

20. Wilhelm S, Tavares AJ, Dai Q, Ohta S, Audet J, Dvorak HF, Chan WC. Analysis of nanoparticle delivery to tumours. Nat Rev Mater. 2016;1:1-12.

21. Price LSL, Stern ST, Deal AM, Kabanov AV, Zamboni WC. A reanalysis of nanoparticle tumor delivery using classical pharmacokinetic metrics. Sci Adv. 2020;6:eaay9249.

22. Ben-David U, Ha G, Tseng YY, Greenwald NF, Oh C, Shih J, McFarland JM, Wong B, Boehm JS, Beroukhim R, Golub TR. Patient-derived xenografts undergo mouse-specific tumor evolution. Nat Genet. 2017:49:1567-75.

23. Pasut G, Paolino D, Celia C, Mero A, Joseph AS, Wolfram J, Cosco D, Schiavon O, Shen H, Fresta M. Polyethylene glycol (PEG)-dendron phospholipids as innovative constructs for the preparation of super stealth liposomes for anticancer therapy. J Control Release. 2015;199:106-13.

24. Nakamura K, Yamashita K, Itoh Y, Yoshino K, Nozawa S, Kasukawa H. Comparative studies of polyethylene glycol-modified liposomes prepared using different PEG-modification methods. Biochim Biophys Acta. 2012;1818:2801-7.

25. Zhang P, Wang Y, Lian J, Shen Q, Wang C, Ma B, Zhang Y, Xu T, Li J, Shao $Y$, et al. Engineering the surface of smart nanocarriers using a pH-/ Thermal-/GSH-responsive polymer zipper for precise tumor targeting therapy in vivo. Adv Mater. 2017;29:1702311.

26. Newman MR, Russell SG, Schmitt CS, Marozas IA, Sheu TJ, Puzas JE, Benoit DSW. Multivalent presentation of peptide targeting groups alters polymer biodistribution to target tissues. Biomacromol. 2018;19:71-84.

27. Gomes-da-Silva LC, Fonseca NA, Moura V, Pedroso de Lima MC, Simoes S, Moreira JN. Lipid-based nanoparticles for siRNA delivery in cancer therapy: paradigms and challenges. Acc Chem Res. 2012;45:1163-71.

28. Elsharkasy OM, Nordin JZ, Hagey DW, de Jong OG, Schiffelers RM, Andaloussi SE, Vader P. Extracellular vesicles as drug delivery systems: why and how? Adv Drug Deliv Rev. 2020;159:332-43.

29. Margolis L, Sadovsky Y. The biology of extracellular vesicles: the known unknowns. PLoS Biol. 2019;17:e3000363.

30. Thery C, Witwer KW, Aikawa E, Alcaraz MJ, Anderson JD, Andriantsitohaina R, Antoniou A, Arab T, Archer F, Atkin-Smith GK, et al. Minimal information for studies of extracellular vesicles 2018 (MISEV2018): a position statement of the International Society for Extracellular Vesicles and update of the MISEV2014 guidelines. J Extracell Vesicles. 2018;7:1535750.

31. Pegtel DM, Gould SJ. Exosomes. Annu Rev Biochem. 2019;88:487-514.

32. Kalluri $R$, LeBleu VS. The biology, function, and biomedical applications of exosomes. Science. 2020. https://doi.org/10.1126/science.aau6977.

33. Patil SM, Sawant SS, Kunda NK. Exosomes as drug delivery systems: a brief overview and progress update. Eur J Pharm Biopharm. 2020;154:259-69.

34. Li YJ, Wu JY, Hu XB, Wang JM, Xiang DX. Autologous cancer cell-derived extracellular vesicles as drug-delivery systems: a systematic review of preclinical and clinical findings and translational implications. Nanomedicine (Lond). 2019;14:493-509.

35. Mehryab F, Rabbani S, Shahhosseini S, Shekari F, Fatahi Y, Baharvand $H$, Haeri A. Exosomes as a next-generation drug delivery system: an update on drug loading approaches, characterization, and clinical application challenges. Acta Biomater. 2020;113:42-62.
36. Kamerkar S, LeBleu VS, Sugimoto H, Yang S, Ruivo CF, Melo SA, Lee JJ, Kalluri R. Exosomes facilitate therapeutic targeting of oncogenic KRAS in pancreatic cancer. Nature. 2017;546:498-503.

37. Matlung HL, Szilagyi K, Barclay NA, van den Berg TK. The CD47-SIRPalpha signaling axis as an innate immune checkpoint in cancer. Immunol Rev. 2017;276:145-64.

38. Colao IL, Corteling R, Bracewell D, Wall I. Manufacturing exosomes: a promising therapeutic platform. Trends Mol Med. 2018;24:242-56.

39. Ayala-Mar S, Donoso-Quezada J, Gallo-Villanueva RC, Perez-Gonzalez VH, Gonzalez-Valdez J. Recent advances and challenges in the recovery and purification of cellular exosomes. Electrophoresis. 2019;40:3036-49.

40. Hood JL. Post isolation modification of exosomes for nanomedicine applications. Nanomedicine (Lond). 2016;11:1745-56.

41. Rankin-Turner S, Vader P, O'Driscoll L, Giebel B, Heaney LM, Davies OG. A call for the standardised reporting of factors affecting the exogenous loading of extracellular vesicles with therapeutic cargos. Adv Drug Deliv Rev. 2021;173:479-91.

42. Jeyaram A, Jay SM. Preservation and storage stability of extracellular vesicles for therapeutic applications. AAPS J. 2017;20:1.

43. Willms E, Cabanas C, Mager I, Wood MJA, Vader P. Extracellular vesicle heterogeneity: subpopulations, isolation techniques, and diverse functions in cancer progression. Front Immunol. 2018;9:738.

44. Huang G, Lin G, Zhu Y, Duan W, Jin D. Emerging technologies for profiling extracellular vesicle heterogeneity. Lab Chip. 2020;20:2423-37.

45. Garcia-Manrique P, Gutierrez G, Blanco-Lopez MC. Fully artificial exosomes: towards new theranostic biomaterials. Trends Biotechnol. 2018:36:10-4

46. Jang SC, Kim OY, Yoon CM, Choi DS, Roh TY, Park J, Nilsson J, Lotvall J, Kim YK, Gho YS. Bioinspired exosome-mimetic nanovesicles for targeted delivery of chemotherapeutics to malignant tumors. ACS Nano. 2013;7:7698-710

47. Wang JM, Li YJ, Wu JY, Cai JX, Wen J, Xiang DX, Hu XB, Li WQ. Comparative evaluation of methods for isolating small extracellular vesicles derived from pancreatic cancer cells. Cell Biosci. 2021;11:37.

48. Lunavat TR, Jang SC, Nilsson L, Park HT, Repiska G, Lasser C, Nilsson JA, Gho YS, Lotvall J. RNAi delivery by exosome-mimetic nanovesicles - Implications for targeting c-Myc in cancer. Biomaterials. 2016;102:231-8.

49. Jeong D, Jo W, Yoon J, Kim J, Gianchandani S, Gho YS, Park J. Nanovesicles engineered from ES cells for enhanced cell proliferation. Biomaterials. 2014;35:9302-10.

50. Oh K, Kim SR, Kim DK, Seo MW, Lee C, Lee HM, Oh JE, Choi EY, Lee DS, Gho YS, Park KS. In vivo differentiation of therapeutic insulin-producing cells from bone marrow cells via extracellular vesicle-mimetic nanovesicles. ACS Nano. 2015;9:11718-27.

51. Kim YS, Kim JY, Cho R, Shin DM, Lee SW, Oh YM. Adipose stem cellderived nanovesicles inhibit emphysema primarily via an FGF2dependent pathway. Exp Mol Med. 2017;49:e284.

52. Kalimuthu S, Gangadaran P, Rajendran RL, Zhu L, Oh JM, Lee HW, Gopal A, Baek SH, Jeong SY, Lee SW, et al. A new approach for loading anticancer drugs into mesenchymal stem cell-derived exosome mimetics for cancer therapy. Front Pharmacol. 2018;9:1116.

53. Kim HY, Kumar H, Jo MJ, Kim J, Yoon JK, Lee JR, Kang M, Choo YW, Song SY, Kwon SP, et al. Therapeutic efficacy-potentiated and diseased organtargeting nanovesicles derived from mesenchymal stem cells for spinal cord injury treatment. Nano Lett. 2018;18:4965-75.

54. Yang Z, Xie J, Zhu J, Kang C, Chiang C, Wang X, Wang X, Kuang T, Chen $F$, Chen Z, et al. Functional exosome-mimic for delivery of siRNA to cancer: in vitro and in vivo evaluation. J Control Release. 2016;243:160-71.

55. Nasiri Kenari A, Kastaniegaard K, Greening DW, Shambrook M, Stensballe A, Cheng L, Hill AF. Proteomic and post-translational modification profiling of exosome-mimetic nanovesicles compared to exosomes. Proteomics. 2019;19:e1800161.

56. Tao SC, Rui BY, Wang QY, Zhou D, Zhang Y, Guo SC. Extracellular vesicle-mimetic nanovesicles transport LncRNA-H19 as competing endogenous RNA for the treatment of diabetic wounds. Drug Deliv. 2018;25:241-55

57. Wu JY, Ji AL, Wang ZX, Qiang GH, Qu Z, Wu JH, Jiang CP. ExosomeMimetic Nanovesicles from Hepatocytes promote hepatocyte proliferation in vitro and liver regeneration in vivo. Sci Rep. 2018;8:2471. 
58. Choo YW, Kang M, Kim HY, Han J, Kang S, Lee JR, Jeong GJ, Kwon SP, Song SY, Go S, et al. M1 macrophage-derived nanovesicles potentiate the anticancer efficacy of immune checkpoint inhibitors. ACS Nano. 2018;12:8977-93.

59. Zhu L, Gangadaran P, Kalimuthu S, Oh JM, Baek SH, Jeong SY, Lee SW, Lee J, Ahn BC. Novel alternatives to extracellular vesicle-based immunotherapy — exosome mimetics derived from natural killer cells. Artif Cells Nanomed Biotechnol. 2018;46:S166-79.

60. Wu JY, Li YJ, Hu XB, Huang S, Luo S, Tang T, Xiang DX. Exosomes and biomimetic nanovesicles-mediated anti-glioblastoma therapy: a headto-head comparison. J Control Release. 2021;336:510-21.

61. Fan Z, Xiao K, Lin J, Liao Y, Huang X. Functionalized DNA enables programming exosomes/vesicles for tumor imaging and therapy. Small. 2019;15:e190361.

62. Guo P, Busatto S, Huang J, Morad G, Moses MA. A facile magnetic extrusion method for preparing endosome-derived vesicles for cancer drug delivery. Adv Funct Mater. 2021. https://doi.org/10.1002/adfm.20200 8326.

63. Jo W, Kim J, Yoon J, Jeong D, Cho S, Jeong H, Yoon YJ, Kim SC, Gho YS, Park J. Large-scale generation of cell-derived nanovesicles. Nanoscale. 2014;6:12056-64.

64. Goh WJ, Zou S, Ong WY, Torta F, Alexandra AF, Schiffelers RM, Storm G, Wang JW, Czarny B, Pastorin G. Bioinspired cell-derived nanovesicles versus exosomes as drug delivery systems: a cost-effective alternative. Sci Rep. 2017;7:14322.

65. Jo W, Jeong D, Kim J, Cho S, Jang SC, Han C, Kang JY, Gho YS, Park J. Microfluidic fabrication of cell-derived nanovesicles as endogenous RNA carriers. Lab Chip. 2014;14:1261-9.

66. Yoon J, Jo W, Jeong D, Kim J, Jeong H, Park J. Generation of nanovesicles with sliced cellular membrane fragments for exogenous material delivery. Biomaterials. 2015:59:12-20.

67. Gao J, Chu D, Wang Z. Cell membrane-formed nanovesicles for diseasetargeted delivery. J Control Release. 2016;224:208-16.

68. Gao J, Wang S, Wang Z. High yield, scalable and remotely drug-loaded neutrophil-derived extracellular vesicles (EVs) for anti-inflammation therapy. Biomaterials. 2017;135:62-73.

69. Go G, Lee J, Choi DS, Kim SS, Gho YS. Extracellular vesicle-mimetic ghost nanovesicles for delivering anti-inflammatory drugs to mitigate gram-negative bacterial outer membrane vesicle-induced systemic inflammatory response syndrome. Adv Healthc Mater. 2019;8:e1801082.

70. Ingato D, Edson JA, Zakharian M, Kwon YJ. Cancer Cell-derived, drugloaded nanovesicles induced by sulfhydryl-blocking for effective and safe cancer therapy. ACS Nano. 2018;12:9568-77.

71. Patty PJ, Frisken BJ. The pressure-dependence of the size of extruded vesicles. Biophys J. 2003;85:996-1004.

72. Olson F, Hunt C, Szoka F, Vail W, Papahadjopoulos D. Preparation of liposomes of defined size distribution by extrusion through polycarbonate membranes. Biochimica et Biophysica Acta BBA Biomembranes. 1979;557:9-23.

73. Liu D, Zhang H, Fontana F, Hirvonen JT, Santos HA. Current developments and applications of microfluidic technology toward clinical translation of nanomedicines. Adv Drug Deliv Rev. 2018;128:54-83.

74. Elvira KS. Microfluidic technologies for drug discovery and development: friend or foe? Trends Pharmacol Sci. 2021;42:518-26.

75. Filipczak N, Pan J, Yalamarty SSK, Torchilin VP. Recent advancements in liposome technology. Adv Drug Deliv Rev. 2020;156:4-22.

76. Zhao Z, McGill J, Gamero-Kubota P, He M. Microfluidic on-demand engineering of exosomes towards cancer immunotherapy. Lab Chip. 2019;19:1877-86.

77. Sezgin E, Kaiser HJ, Baumgart T, Schwille P, Simons K, Levental I. Elucidating membrane structure and protein behavior using giant plasma membrane vesicles. Nat Protoc. 2012;7:1042-51.

78. Rideau E, Dimova R, Schwille P, Wurm FR, Landfester K. Liposomes and polymersomes: a comparative review towards cell mimicking. Chem Soc Rev. 2018;47:8572-610.

79. Krause MR, Regen SL. The structural role of cholesterol in cell membranes: from condensed bilayers to lipid rafts. Acc Chem Res. 2014;47:3512-21.

80. Lu M, Huang Y. Bioinspired exosome-like therapeutics and delivery nanoplatforms. Biomaterials. 2020;242:119925.
81. Liu C, Su C. Design strategies and application progress of therapeutic exosomes. Theranostics. 2019;9:1015-28.

82. De La Pena H, Madrigal JA, Rusakiewicz S, Bencsik M, Cave GW, Selman A, Rees RC, Travers PJ, Dodi IA. Artificial exosomes as tools for basic and clinical immunology. J Immunol Methods. 2009;344:121-32.

83. Martinez-Lostao L, Garcia-Alvarez F, Basanez G, Alegre-Aguaron E, Desportes P, Larrad L, Naval J, Martinez-Lorenzo MJ, Anel A. Liposomebound APO2L/TRAIL is an effective treatment in a rabbit model of rheumatoid arthritis. Arthritis Rheum. 2010;62:2272-82.

84. De Miguel D, Basanez G, Sanchez D, Malo PG, Marzo I, Larrad L, Naval J, Pardo J, Anel A, Martinez-Lostao L. Liposomes decorated with Apo2L/ TRAlL overcome chemoresistance of human hematologic tumor cells. Mol Pharm. 2013;10:893-904.

85. Li K, Chang S, Wang Z, Zhao X, Chen D. A novel micro-emulsion and micelle assembling method to prepare DEC205 monoclonal antibody coupled cationic nanoliposomes for simulating exosomes to target dendritic cells. Int J Pharm. 2015;491:105-12.

86. Lu M, Zhao X, Xing H, Liu H, Lang L, Yang T, Xun Z, Wang D, Ding P. Cellfree synthesis of connexin 43-integrated exosome-mimetic nanoparticles for siRNA delivery. Acta Biomater. 2019;96:517-36.

87. Vazquez-Rios AJ, Molina-Crespo A, Bouzo BL, Lopez-Lopez R, MorenoBueno G, de la Fuente M. Exosome-mimetic nanoplatforms for targeted cancer drug delivery. J Nanobiotechnol. 2019;17:85.

88. Molinaro R, Martinez JO, Zinger A, De Vita A, Storci G, Arrighetti N, De Rosa E, Hartman KA, Basu N, Taghipour N, et al. Leukocyte-mimicking nanovesicles for effective doxorubicin delivery to treat breast cancer and melanoma. Biomater Sci. 2020;8:333-41.

89. Li YJ, Wu JY, Hu XB, Ding T, Tang T, Xiang DX. Biomimetic liposome with surface-bound elastase for enhanced tumor penetration and chemoimmumotherapy. Adv Healthc Mater. 2021. https://doi.org/10.1002/ adhm.202100794.

90. Zhang KL, Wang YJ, Sun J, Zhou J, Xing C, Huang G, Li J, Yang H. Artificial chimeric exosomes for anti-phagocytosis and targeted cancer therapy. Chem Sci. 2019;10:1555-61.

91. Li J, Peng K, Li Y, Wang J, Huang J, Yan Y, Wang D, Tang BZ. Exosomemimetic supramolecular vesicles with reversible and controllable fusion and fission*. Angew Chem Int Ed Engl. 2020;59:21510-4.

92. Kameritsch P, Renkawitz J. Principles of leukocyte migration strategies. Trends Cell Biol. 2020;30:818-32.

93. Molinaro R, Corbo C, Martinez JO, Taraballi F, Evangelopoulos M, Minard S, Yazdi IK, Zhao P, De Rosa E, Sherman MB, et al. Biomimetic proteolipid vesicles for targeting inflamed tissues. Nat Mater. 2016;15:1037-46.

94. Li J, Shi K, Drechsler M, Tang BZ, Huang J, Yan Y. A supramolecular fluorescent vesicle based on a coordinating aggregation induced emission amphiphile: insight into the role of electrical charge in cancer cell division. Chem Commun (Camb). 2016;52:12466-9.

95. Sato YT, Umezaki K, Sawada S, Mukai SA, Sasaki Y, Harada N, Shiku H, Akiyoshi K. Engineering hybrid exosomes by membrane fusion with liposomes. Sci Rep. 2016;6:21933.

96. Lv Q, Cheng L, Lu Y, Zhang X, Wang Y, Deng J, Zhou J, Liu B, Liu J. Thermosensitive exosome-liposome hybrid nanoparticle-mediated chemoimmunotherapy for improved treatment of metastatic peritoneal cancer. Adv Sci (Weinh). 2020;7:2000515.

97. Lin Y, Wu J, Gu W, Huang Y, Tong Z, Huang L, Tan J. Exosome-liposome hybrid nanoparticles deliver CRISPR/Cas9 system in MSCs. Adv Sci (Weinh). 2018;5:1700611.

98. Piffoux M, Silva AKA, Wilhelm C, Gazeau F, Tareste D. Modification of extracellular vesicles by fusion with liposomes for the design of personalized biogenic drug delivery systems. ACS Nano. 2018;12:6830-42.

99. Rayamajhi S, Nguyen TDT, Marasini R, Aryal S. Macrophage-derived exosome-mimetic hybrid vesicles for tumor targeted drug delivery. Acta Biomater. 2019;94:482-94.

100. Jhan YY, Prasca-Chamorro D, Palou Zuniga G, Moore DM, Arun Kumar S, Gaharwar AK, Bishop CJ. Engineered extracellular vesicles with synthetic lipids via membrane fusion to establish efficient gene delivery. Int J Pharm. 2020;573:118802.

101. Sun L, Fan M, Huang D, Li B, Xu R, Gao F, Chen Y. Clodronate-loaded liposomal and fibroblast-derived exosomal hybrid system for enhanced drug delivery to pulmonary fibrosis. Biomaterials. 2021;271:120761.

102. Liang Y, Duan L, Lu J, Xia J. Engineering exosomes for targeted drug delivery. Theranostics. 2021;11:3183-95. 
103. Paliwal SR, Paliwal R, Vyas SP. A review of mechanistic insight and application of $\mathrm{pH}$-sensitive liposomes in drug delivery. Drug Deliv. 2015;22:231-42

104. Kumar Pramanik S, Losada-Pe Rez P, Reekmans G, Carleer R, D'Olieslaeger M, Vanderzande D, Adriaensens P, Ethirajan A. Physicochemical characterizations of functional hybrid liposomal nanocarriers formed using photo-sensitive lipids. Sci Rep. 2017;7:46257.

105. Abri Aghdam M, Bagheri R, Mosafer J, Baradaran B, Hashemzaei M, Baghbanzadeh A, de la Guardia M, Mokhtarzadeh A. Recent advances on thermosensitive and $\mathrm{pH}$-sensitive liposomes employed in controlled release. J Control Release. 2019;315:1-22.

106. van Niel G, D'Angelo G, Raposo G. Shedding light on the cell biology of extracellular vesicles. Nat Rev Mol Cell Biol. 2018;19:213-28.

107. LeBleu VS, Kalluri R. Exosomes as a multicomponent biomarker platform in cancer. Trends Cancer. 2020;6:767-74.

108. Hornung S, Dutta S, Bitan G. CNS-derived blood exosomes as a promising source of biomarkers: opportunities and challenges. Front Mol Neurosci. 2020;13:38

109. Wei W, Ao Q, Wang X, Cao Y, Liu Y, Zheng SG, Tian X. Mesenchymal stem cell-derived exosomes: a promising biological tool in nanomedicine. Front Pharmacol. 2020;11:590470.

110. Escude Martinez de Castilla P, Tong L, Huang C, Marios Sofias A, Pastorin G, Chen X, Storm G, Schiffelers RM, Wang JW. Extracellular vesicles as a drug delivery system: a systematic review of preclinical studies. Adv Drug Deliv Rev. 2021;175:113801.

111. Gao Y, Zhang H, Zhou N, Xu P, Wang J, Gao Y, Jin X, Liang X, Lv J, Zhang $Y$, et al. Methotrexate-loaded tumour-cell-derived microvesicles can relieve biliary obstruction in patients with extrahepatic cholangiocarcinoma. Nat Biomed Eng. 2020;4:743-53.

112. Ma J, Zhang $Y$, Tang $K$, Zhang H, Yin X, Li Y, Xu P, Sun Y, Ma R, Ji T, et al. Reversing drug resistance of soft tumor-repopulating cells by tumor cell-derived chemotherapeutic microparticles. Cell Res. 2016;26:713-27.
113. Tang K, Zhang Y, Zhang H, Xu P, Liu J, Ma J, Lv M, Li D, Katirai F, Shen GX, et al. Delivery of chemotherapeutic drugs in tumour cell-derived microparticles. Nat Commun. 2012;3:1282.

114. Perocheau D, Touramanidou L, Gurung S, Gissen P, Baruteau J. Clinical applications for exosomes: are we there yet? Br J Pharmacol. 2021;178:2375-92.

115. Wang J, Chen D, Ho EA. Challenges in the development and establishment of exosome-based drug delivery systems. J Control Release. 2021;329:894-906.

116. Yang XX, Sun C, Wang L, Guo XL. New insight into isolation, identification techniques and medical applications of exosomes. J Contro Release. 2019;308:119-29.

117. Donoso-Quezada J, Ayala-Mar S, Gonzalez-Valdez J. State-of-the-art exosome loading and functionalization techniques for enhanced therapeutics: a review. Crit Rev Biotechnol. 2020;40:804-20.

118. Kusuma GD, Barabadi M, Tan JL, Morton DAV, Frith JE, Lim R. To protect and to preserve: novel preservation strategies for extracellular vesicles. Front Pharmacol. 2018;9:1199.

119. Bari E, Perteghella S, Catenacci L, Sorlini M, Croce S, Mantelli M, Avanzini MA, Sorrenti M, Torre ML. Freeze-dried and GMP-compliant pharmaceuticals containing exosomes for acellular mesenchymal stromal cell immunomodulant therapy. Nanomedicine (Lond). 2019;14:753-65.

\section{Publisher's Note}

Springer Nature remains neutral with regard to jurisdictional claims in published maps and institutional affiliations.
Ready to submit your research? Choose BMC and benefit from:

- fast, convenient online submission

- thorough peer review by experienced researchers in your field

- rapid publication on acceptance

- support for research data, including large and complex data types

- gold Open Access which fosters wider collaboration and increased citations

- maximum visibility for your research: over $100 \mathrm{M}$ website views per year

At $\mathrm{BMC}$, research is always in progress.

Learn more biomedcentral.com/submissions 